\title{
UMA VISÃO SOBRE OS PRECEDENTES JUDICIAIS E SUA EFICÁCIA NO SISTEMA BRASILEIRO ATUAL
}

\author{
A VISION ON LEGAL PRECEDENT AND ITS EFFECTIVENESS \\ IN THE BRAZILIAN SYSTEM CURRENT
}

\author{
Nelson Finotti SILVA ${ }^{1}$ \\ Fernanda Molina de Carvalho STANÇA ${ }^{2}$
}

Artigo recebido em: 06/07/2016

Artigo aprovado em: 24/08/2016

\begin{abstract}
RESUMO: O objetivo do presente artigo é investigar a importância da força vinculante dos precedentes judiciais no direito brasileiro, pois com as modificações trazidas com a vigência do Novo Código de Processo Civil (Lei no 13.105/2015), em vigor desde o dia 18 de março de 2016, inegavelmente trouxe reflexos e irradiará em todos os outros ramos do Direito, sendo que especialmente no tocante ao tema dos precedentes judiciais, será necessário fazer uma releitura, pois o que já podemos perceber é a ampliação do caráter vinculante dos precedentes judiciais, aperfeiçoando sua previsão e o dever de motivação das decisões judiciais, visando combater arbitrariedades e contribuir para se alcançar a uniformidade e a estabilidade da jurisprudência. Discorre-se inicialmente sobre o funcionamento deste sistema de precedente judicial, seus conceitos e aplicações. Tem-se, ainda, como ponto de partida o princípio da força normativa da Constituição Fe-
\end{abstract}

\footnotetext{
1 Procurador do Estado de São Paulo desde 1989, em exercício na Consultoria Jurídica da Faculdade de Medicina de São José do Rio Preto - FAMERP. Doutor em Direito Processual Civil pela Pontifícia Universidade Católica de São Paulo (2008), mestre em Direito do Estado pela Universidade de Franca (2001) e graduado em Direito pela Faculdades Metropolitanas Unidas (1985). É professor titular concursado da cadeira de processo civil da Faculdade de Filosofia Ciências e Letras de Catanduva do curso de Pós-Graduação "latu sensu", professor da Pós-Graduação «stricto sensu" - Mestrado - da Fundação de Ensino Euripedes Soares da Rocha (UNIVEM - Centro Universitário Eurípedes de Marilia), membro efetivo do Instituto Brasileiro de Direito Processual - IBDP. E-mail: nfinotti1@gmail.com
}

${ }^{2}$ Advogada, Mestranda pelo Centro Universitário Eurípides de Marília. UNIVEM.

E-mail: molina_fer@yahoo.com.br 
deral, procura-se demonstrar que a análise desse trabalho também versa sobre o reconhecimento da vinculação das razões de decidir fixadas pelos Tribunais Superiores. Por fim, será descrito alguns argumentos favoráveis e outros contrários ao reconhecimento dessa vinculação, tendo em vista a expansão da jurisdição constitucional e a valorização dos direitos fundamentais.

PALAVRAS-CHAVE: Precedente Judicial, Ratio Decidendi, Efeito Vinculante, Novo Código de Processo Civil.

\begin{abstract}
The purpose of this article is to investigate the importance of the binding force of judicial precedents in Brazilian law, as with the modifications brought to the effect of the new Civil Procedure Code (Law n $\left.{ }^{\circ} 13.105 / 2015\right)$, in force since March 18, 2016 undeniably brought reflexes and radiate in all other areas of law, and especially with regard to the issue of judicial precedent, it will be necessary to re-read, for what we notice is the extension of the binding character of judicial precedents, perfecting your forecast and the duty of motivation of judicial decisions, to combat arbitrariness and contribute to achieving uniformity and stability of jurisprudence. It elaborates on the first operation of this judicial precedent system, concepts and applications. There is, still, as a starting point the principle of normative force of the Constitution, sought to demonstrate that the analysis of this work also deals with the recognition of the linkage of the reasons for deciding set by higher courts. Finally, it will be described some other arguments for and against recognition of this link, with a view to expanding the constitutional court and the enhancement of fundamental rights.
\end{abstract}

KEYWORDS: Judicial Precedent, ratio decidendi, Binding Effect, New Civil Procedure Code. 


\section{Introdução}

O presente estudo pretende demonstrar que atualmente no Poder Judiciário verifica-se a ausência de uniformização e estabilidade da jurisprudência, pois as decisões proferidas pelos juízes apresentam diversos entendimentos e interpretações acerca de um mesmo assunto.

Por sua vez, também podemos observar a falta de estabilidade nas decisões, pois são constantemente alteradas, não tendo, portanto entendimentos sedimentados, gerando assim, uma grande e preocupante insegurança jurídica.

Essa multiplicidade de decisões revela um sistema jurídico incoerente, sendo que esse estudo procura abordar a força dos precedentes judiciais, pois sua relevância está estampada com as alterações em nosso sistema processual, a partir da análise do Novo Código de Processo Civil e seus dispositivos, pois dão relevância à jurisprudência reiterada dos Tribunais Superiores, com a imposição para que os Tribunais uniformizem sua jurisprudência e a mantenham estável, íntegra e coerente, como forma de amenizar e combater a insegurança jurídica e concretizar plenamente o princípio da igualdade para todos que necessitam buscar uma resposta do Poder Judiciário.

Nota-se carência de estudos sobre o assunto no país, pois são recentes as alterações elencadas na legislação processual civil, bem como ainda seria precoce arriscar uma solução acerca do tema proposto.

\section{Dos sistemas jurídicos: commow law e civil law}

Primeiramente tem-se que explicitar a divisão dos sistemas jurídicos entre os países de origem anglo-saxônica (commow law), sendo que podemos citar a título de exemplo a Inglaterra e os Estados Unidos, e aqueles de origem romano-germânica (civil law), como exemplo podemos citar os países da América Latina. Pode-se notar que são tradições jurídicas e políticas muito diferentes e, consequentemente, com características distintas.

No sistema da commow law, adota-se um sistema costumeiro, aplicado pela jurisprudência, no qual prevalece a pacificação das partes envolvidas no litígio. Há uma visão muito bem desenvolvida dos precedentes judiciais, que são dotados de eficácia vinculante não só para a Corte Superior da qual proveio, como para juízos que lhe são hierarquicamente inferiores. Nesse sistema, os precedentes possuem caráter vinculativo, de observância obrigatória para os 
demais órgãos jurisdicionais.

A força vinculante conferida aos precedentes é justificada pela necessidade de igualdade, sendo que esta igualdade é atingida pela seleção de aspectos do caso concreto a ser julgado, que devem ser considerados relevantes, para que esse caso seja considerado semelhante a outro, e decidido da mesma forma (WAMBIER, 2009, p. 129).

Didier Jr, disserta que o denominado sistema do common law, informado pela teoria da stare decisis, que significa mantenha-se a decisão e não se moleste o que foi decidido. (DIDIER JR, 2011, p. 389).

Nas palavras de René David (1996, p. 332-333):

A atenção dos juristas se concentra basicamente sobre a atividade dos Tribunais Superiores, pelo fato destes não se limitarem a resolver os processos; as suas decisões, de grande alcance constituem "precedentes" que devem ser seguidos no futuro e pelo estudo dos quais se poderá conhecer qual é o direito na Inglaterra. A maior parte dos assuntos é resolvida, no entanto, fora da alçada daqueles tribunais, por jurisdições inferiores ou organismos "quase judiciários" e as sentenças que proferem têm seu interesse limitado à espécie por eles julgada.

Podemos verificar que toda a jurisdição no sistema commow law está ligada às decisões tomadas anteriormente por um tribunal hierarquicamente superior, sendo que apenas os precedentes produzidos que são obrigatórios e imperativos.

Por outro lado, nos países que seguem a linha do civil law, Itália, França, na Alemanha, na Espanha, Portugal, assim, como em toda a América Latina, e facilmente perceptível no Brasil, onde sempre seguiu-se o caminho que a lei é a fonte primária do direito, com fundamento o positivismo jurídico, ou seja, é um direito escrito, no qual a jurisdição é estruturada preponderantemente com a finalidade de atuação do direito objetivo, os precedentes tradicionalmente e em regra, apenas orientam, mas não vinculam o pedido ou o julgamento de casos posteriores sobre a mesma matéria. Devido a isso, o precedente funciona como argumento da disposição legal. Perceber que nesse sistema busca-se a segurança jurídica.

A segurança jurídica está associada à ideia de estabilidade e continuidade da ordem jurídica, bem como de previsibilidade das consequências jurídicas de determinada conduta. (MARINONI, 2010, p. 121). 
Nesse sentido explica Canotilho (1993, p. 374):

A durabilidade e permanência da própria ordem jurídica, da paz jurídico social e das situações jurídicas, sendo que outra garantística jurídico-subjectiva dos cidadãos legitima a confiança na permanência das respectivas situações jurídicas.

Um dos momentos mais relevantes para a fixação das características do civil law ocorreria durante a Revolução Francesa. A transferência do poder central do monarca para a nação gerou o ambiente em que nasceu a base do raciocínio jurídico desse sistema (WAMBIER, 2009, p. 126).

Verifica-se assim que enquanto o commow law evoluiu de um direito primitivo, dando segurança jurídica aos seus jurisdicionados por meio do respeito às decisões pretéritas através da força vinculante atribuída a elas, o civil law surgiu com os ideias da Revolução Francesa, codificando a lei, com intuito de não abrir espaços para a criação ou interpretação.

Pode-se observar que a teoria dos precedentes judiciais vem ganhando cada vez mais destaque no nosso ordenamento jurídico, vinculado à tradição do civil law, mas não se pode deixar de perceber algumas evidências da aplicação e referências adotados na commow law e vice versa. É inegável a aproximação dos dois sistemas citados, pois há uma tendência à uniformização das decisões judiciais, e a força vinculante dos precedentes judiciais.

No sistema do civil law, apesar de haver preponderância das leis, há espaço para os precedentes judiciais. A diferença é que no civil law o precedente tem a função de orientar a interpretação da lei, mas não necessariamente de obrigar que o julgador adote o mesmo fundamento de decisão anteriormente proferida e que tenha como pano de fundo situação jurídica semelhante.

É essa desobrigação de vinculação aos precedentes judiciais no Brasil que deve causar preocupação. A igualdade, a coerência e a previsibilidade das decisões judiciais são necessárias à própria estabilidade do Direito. Na distribuição da justiça é inadmissível pensar que situações juridicamente idênticas sejam julgadas de maneira distintas por órgãos de um mesmo tribunal.

Não se pode comparar a buscar pela tutela jurisdicional com um jogo de loteria e, por isso mesmo, é preciso compatibilizar a força dos precedentes judiciais e a necessidade de individualização do Direito. Se existir fundamento suficiente para afastar um entendimento já consolidado, deve o magistrado exercer plenamente o seu livre convencimento, sem qualquer vinculação a julgamentos 
anteriores. Caso contrário, será necessário que se busque, preferencialmente junto aos Tribunais Superiores, a interpretação uniformizada sobre o tema.

Ocorre que a lei, por ser interpretada de vários modos, inclusive a partir de percepções morais do próprio julgador, não se mostra suficiente a assegurar aos jurisdicionados a mínima segurança jurídica que se espera de um Estado Democrático de Direito.

O que se pretende, então, com a adoção de um sistema de precedentes, é oferecer soluções semelhantes para questões que possuam o mesmo fundamento jurídico, evitando, assim, a utilização excessiva de recursos e o aumento na quantidade de demandas.

É importante que se enfrente, preliminarmente, algumas definições e conceituações dos precedentes judiciais, para posteriormente identificar suas aplicações no cenário jurídico nacional.

Nas precisas palavras do jurista STRECK e ABBOUD (2013, p. 42):

Precedente é uma decisão de um Tribunal com aptidão a ser reproduzida seguida pelos tribunais inferiores, entretanto, sua condição de precedente dependerá de ele ser efetivamente seguido na resolução de casos análogos- similares.

Nesta mesma linha, TUCCI (2004, p.11-12) afirma que o precedente então nasce como uma regra de um caso e, em seguida, terá ou não o destino de tornar-se a regra de uma série de casos análogos.

Precedente não é acórdão; não são configurados pela ementa. Precedentes são configurados pelo corpo da decisão.

Iniciando o trabalho com a definição dos precedentes, parece ao leitor, em um primeiro momento, que a expressão precedente vem com o Novo Código de Processo Civil, o que não é verdade, pois já temos o sistema de precedentes no Brasil, o que vai incorporar o legislador é a tentativa de massificação desses precedentes. Podemos perceber que os precedentes já eram uma realidade no Código de Processo Civil de 1973.

Cada precedente terá, desse modo, uma ratio decidendi, que pode ser conceituado como:

O critério decisional, ou seja, a regra que está subjacente à decisão; é o princípio de direito adotado para definir o conteúdo da demanda; é a premissa ou passagem lógica que se revela necessária para se alcançar a decisão do caso; é a regra ou princípio 
que constitui a condição necessária ou suficiente; é o princípio de direito contido na decisão judicial e que é suficiente para decidir o caso concreto; é a argumentação explícita ou implícita necessária ou suficiente para definir o caso e por último, é a relação resolução motivada do caso e o próprio caso, ou seja, o fato e as questões jurídicas inerentes (STRECK, ABBOUD, 2013, p. 43).

Em relação ao conceito, propriamente dito, da ratio decidendi, pode-se citar a definição dos juristas DIDIER JUNIOR, BRAGA e OLIVEIRA (2009, v. 2, p. 381) como o conjunto de fundamentos jurídicos que sustentam a decisão; a opção hermenêutica adotada na sentença, sem a qual a decisão não teria sido proferida como foi; trata-se da tese jurídica acolhida pelo julgador no caso concreto.

Demais disso, é importante enfatizar que a ratio decidendi de uma decisão cabe aos juízes, em momento posterior, ao examinarem-na como precedente, extrair a "norma legal" (abstraindo-a do caso) que poderá ou não incidir na situação concreta (TUCCI, 2004, p. 175).

Os demais elementos componentes da decisão que deu origem ao precedente, tais quais os que não possuem influência direta no provimento decisório, que são apenas argumentos de passagem, ou, conforme definição de TUCCI, antes citada, que retratam apenas as circunstâncias de fato que embasam a controvérsia, constituem o chamado obter dictum e não vinculam os casos posteriores. O obter dictum é apenas uma opinião, ou uma observação, um comentário lateral. Segundo STRECK (2013, p. 44), obter dictum corresponde ao enunciado, interpretação jurídica, ou uma argumentação ou fragmento de argumentação jurídica, expressamente contidos na decisão, cujo conteúdo e presença são irrelevantes para a solução final da demanda.

O precedente possui um holding, que irradia o efeito vinculante para todo o sistema. Isto não está na Constituição, nem na lei e sim na tradição, sendo que a aplicação não se dá automaticamente, pois nesse sistema sempre cabe examinar que se o princípio que se pode extrair do precedente constitui a fundamentação da decisão ou tão somente o dictum (STRECK; ABBOUD, 2013, p. 30).

Feita essas breves conceituações, podemos suscitar algumas indagações, e debates que sempre surgem a respeito do presente tema, como por exemplo: o número de recursos que tramitam no Poder Judiciário justifica a quantidade de jurisprudência defensiva dos Tribunais brasileiros? Qual o sistema que vamos adotar daqui por diante? Qual o papel do juiz na criação e aplicação do direito? Qual o papel do juiz na fundamentação jurídica? Temos que refletir o 
futuro e interpretação do processo civil com a entrada no novo Código.

Atualmente, em virtude do impacto do constitucionalismo e do neoconstitucionalismo, não só há nítida aproximação entre as funções dos juízes de common law e civil law, como visível proximidade entre os precedentes ditos de criação do direito e os interpretativos. Mais do que tudo, esta proximidade permite evidenciar a importância dos precedentes no sistema judicial brasileiro, em que os precedentes têm e terão nítida feição interpretativa.

AGRA disserta: "o neoconstitucionalismo tem como uma de suas marcas a concretização das prestações materiais prometidas pela sociedade, servindo como ferramenta para a implantação de um Estado Democrático Social de Direito" (2008, p. 41).

Ainda destacando os pontos marcantes do neoconstitucionalismo, diz que a Constituição passa a ser o centro do sistema, marcada por uma intensa carga valorativa, sendo que a incorporação explícita de valores e opções políticas nos textos constitucionais, sobretudo no que diz respeito à promoção da dignidade humana e dos direitos fundamentais (LENZA, 2012, p. 63).

No Brasil, o movimento neoconstitucionalista somente ganhou força em 1988, representando a confirmação da ideia de que só a instrumentalidade do processo não basta, afinal de nada adiantarão os instrumentos colocados à disposição dos indivíduos se não houver um direito material a ser preenchido nem houver vinculação absoluta de qualquer comando legal/judicial à Constituição.

O precedente é uma realidade inerente a qualquer sistema jurídico, seja da civil law ou da common law, distinguindo-se apenas, quanto ao grau de eficácia que possui.

O Poder Judiciário atualmente assume um novo papel interpretativo com a revolução dos direitos humanos e consequente judicialização da política. A propósito, sobre o constitucionalismo, CANOTILHO (1993, p. 51) conceitua como uma teoria que ergue o princípio do governo limitado indispensável à garantia dos direitos em dimensão estruturante da organização político-social de uma comunidade.

Neste sentido, o constitucionalismo representa a limitação do poder do Estado por meio de uma Constituição e da prevalência dos direitos fundamentais, afastando a ideia de poder autoritário.

No tocante ao neoconstitucionalismo, a doutrina passa a desenvolver uma nova perspectiva em relação ao constitucionalismo, chamada de neoconstitucionalismo, que tem como objetivo desenvolver um novo modo de compreender, 
interpretar e aplicar o Direito, de modo a concretizar os direitos fundamentais.

Percebe-se uma judicialização da política e das relações sociais, pois tudo deságua no Pode Judiciário. Devido a isso, temos o deslocamento do Poder Legislativo e do Poder Executivo para o Poder Judiciário, que passa a ser protagonista de ações, chegando até mesmo, ainda que excepcionalmente a implementar políticas públicas.

É interessante perceber que a nova dimensão de poder atribuída ao juiz de civil law, em razão do constitucionalismo e da técnica legislativa das cláusulas gerais, tem repercussão sobre a dignidade dos fatos em nosso sistema. Como o princípio não se limita a emoldurar fatos e atribuir-lhes consequência jurídica, tendo textura mais aberta e escopo mais generalizado, a racionalização da sua adoção exige a detida identificação das particularidades fáticas do caso concreto. Ademais, as cláusulas gerais, diante do seu próprio propósito, não podem ter a sua aplicação justificada de maneira racional sem a identificação dos fatos sobre os quais estão a incidir.

Novo Código de Processo Civil possui o Livro III, entitulado como Dos Processos nos Tribunais e dos Meios de Impugnação das Decisões Judiciais, sendo que em seu Título I, contém regras relativas ao "Processo nos Tribunais", onde está regulamentado o dever de uniformização estabilidade da jurisprudência, mantendo-a estável, íntegra e coerente (art. 926), sendo previsto nos incisos seguintes a observação de enunciados correspondentes à súmula da jurisprudência dominante; a determinação de que órgãos fracionários sigam orientação do plenário, e órgão superiores aos quais se estiverem vinculados; vem a previsão da jurisprudência pacificada, bem como a previsão da observação da jurisprudência do Supremo Tribunal Federal e Tribunais Superiores, dentre outras disposições inerente à teoria dos precedentes.

O problema do sistema vinculante no Brasil chama-se divergência interpretativa, e isso em processo repetitivo gera instabilidade da jurisprudência.

Uma das grandes bandeiras do Novo Código é a ampliação do sistema de precedentes no Brasil, pois permite-se duas conclusões de imediato: diminuição da divergência interpretativa e a diminuição do poder de decisão do magistrado de $1^{\circ}$ grau.

Um dos grandes pilares dos precedentes é o incidente de resolução de demandas repetitivas, vedação do poder criativo do juiz, mas em compensação se cria um sistema estável de interpretação judicial. Será que um juiz pode, dentro do seu poder argumentativo simples, não concordar com o precedente 
no novo Código de Processo Civil? Será que um juiz dentro da hermenêutica jurídica, poderá simplesmente afastar um precedente de um Tribunal Superior porque entende de forma contrária? A resposta é negativa, pois a desobediência hierárquica é um dos pontos negativos do sistema de vinculação de precedentes no Brasil. Há uma necessidade de obediência. O juiz é obrigado a atender precedentes do seu Tribunal e dos Tribunais Superiores.

A força vinculante dos precedentes também poderia ser visto como fator equalizador de situações desiguais, visto que a necessidade de se respeitar os precedentes impediria o tratamento diferenciado das situações que, por não serem iguais, não poderiam ser tratadas de maneira uniforme (MARINONI, 2010, p. 195).

Podemos observar o lado positivo dada à força obrigatória dos precedentes, citando assim, a diminuição de recursos, diminuição de demandas judiciais, uniformização dos entendimentos, dando assim, segurança jurídica, criação de um advogado com o perfil mais consultivo do que com um perfil litigioso.

Todavia, supõe-se que a força obrigatória conferida ao precedente judicial tonaria o direito imobilizado no decorrer do tempo, uma vez que impediria o desenvolvimento da doutrina e da jurisprudência, uma vez que gerará o engessamento das decisões do Poder Judiciário e consequentemente a vedação do acesso à justiça, uma vez que pode gerar injustiças pelo fato da não análise e considerações acerca das peculiaridades de cada caso concreto.

Sustenta-se ainda, que obrigar o juiz a decidir de acordo com um precedente violaria sua independência. Mas rebatendo essa tese MARINONI (2010, p. 206) ensina:

É preciso não confundir independência dos juízes com ausência de unidade, sob pena de, ao invés de se ter um sistema racional e isonomicamente distribui justiça, ter-se algo que, mais do que falhar aos fins a que se destina, beira um manicômio, onde vozes irremediavelmente contrastantes, de forma ilógica e improducente, se digladiam.

Nessa linha o autor ainda que a vinculação dos precedentes, ao invés de negar, fortalece a justiça, pois a previsibilidade elimina a litigiosidade e evita a "propositura de demandas em um ambiente aberto a soluções díspares, que inevitavelmente desgastam e enfraquecem o Poder Judiciário (MARINONI, 2010, p. 211). 
Tendo em vista a abordagem de alguns argumentos contrários e favoráveis à força obrigatória dos precedentes, é possível se inferir que as teses contrárias não resistem a uma análise racional da questão, o que demonstra não haver qualquer óbice com a obrigatoriedade dos precedentes no Brasil, como meio de se garantir a uniformidade e a estabilidade da jurisprudência.

\section{A força normativa dos precedentes no novo código de processo civil}

O texto do Novo Código de Processo Civil (Lei $\left.n^{0} 13.105 / 2015\right)$ foi sancionado pela Presidente da República em 16 de março de 2015, e publicado oficialmente em 17 de março de 2015, com "vacatio legis" de um ano após a sua publicação, sendo que entrou em vigor no dia 18 de março de 2016.

Podemos verificar que trata-se do primeiro Código de Processo Civil editado sob a égide da atual Constituição Federal, inserindo-se portanto, no contexto do Estado Constitucional de Direito, diversamente do Código de Processo Civil anterior. Hoje, é reconhecido pela doutrina a posição central que ocupa no sistema jurídico, pois é dela que se irradiam valores através dos quais devem ser criadas, interpretadas e aplicadas as normas jurídicas, inclusive as relativas ao Direito Processual Civil (CUNHA, 2012).

Por estar inserido no contexto do Estado Constitucional, o Novo Código de Processo Civil reflete seus valores e fundamentos, com observância dos princípios constitucionais.

Da leitura do novo Código de Processo Civil, verifica-se que o legislador preocupou-se em dar novos rumos ao processualismo civil, indo de encontro de forma direta e positiva, à Constituição Federal, com a introdução de amplos direitos e garantias fundamentais as partes e ao processo.

Sobre o Novo Código de Processo Civil, Elpídio Donizetti (2012), um dos integrantes da comissão de juristas responsáveis pela elaboração do anteprojeto do novo código disserta:

Vale ressaltar que esse dispositivo consiste na materialização das características do neoconstitucionalismo: normatividade da constituição (força normativa), superioridade (material) da constituição, centralidade da constituição (a constituição está no centro do ordenamento jurídico), rematerialização da constituição (constituições mais prolixas, já que tratam de diversas matérias), 
ubiqüidade da constituição (onipresença da constituição em todos os ramos do Direito), constelação plural de valores (adoção de diversos princípios não homogêneos), onipotência judicial (no lugar da autonomia do legislador ordinário), valoração dos princípios (utilização maior da ponderação).

Por sua vez, Virgílio Afonso da Silva (2008, p. 39-40), ensina sobre as adaptações das leis à Constituição, assim escreveu:

A mais efetiva, e, ao menos em tese, a menos problemática forma de constitucionalização do direito é realizada por meio de reformas, pontuais ou globais, na legislação infraconstitucional. É parte da tarefa legislativa adaptar a legislação ordinária às prescrições constitucionais de caráter dirigente, realizá-la por meio da legislação.

Em estudo aprofundado sobre os precedentes judiciais no Brasil, Tiago Asfor Rocha Lima (2013, p. 480), explica que o nosso sistema de precedentes ainda está incompleto e depende de algumas imprescindíveis correções para que dele se possa extrair a finalidade esperada.

Conforme assevera DONIZETTI (2015):

Embora o Brasil possua um sistema jurídico essencialmente baseado na civil law, é possível constatar que os precedentes judiciais estão sendo aos poucos adotados pela legislação processual civil com a finalidade de imprimir maior segurança jurídica aos jurisdicionados a maior celeridade ao trâmite processual. No projeto do Novo Código de Processo Civil é possível perceber a intenção do legislador e aproveitar os fundamentos do commow law e do stare decisis, com o objetivo de privilegiar a busca pela uniformização e estabilização da jurisprudência e garantir a efetividade do processo, notadamente das garantias constitucionais.

De fato, não é incomum encontrar resistência na doutrina e nos tribunais acerca da aplicação dos precedentes judiciais. No entanto, em razão da lenta velocidade pela qual se processam as alterações legislativas no Brasil, a tendência é o desenvolvimento da jurisprudência -que é a reiterada aplicação de um precedente - como forma de solucionar as situações que não podem ser resolvidas por meio da aplicação literal da lei.

Pensando nisso, o Novo Código de Processo Civil trouxe importantes 
mecanismos de aperfeiçoamento do sistema de precedentes judiciais e, consequentemente, de uniformização e estabilização da jurisprudência pátria. Ocorre que todas previsões trazida pelo novo código são denominadas jurisprudência, sem haver a distinção portanto de outros institutos como os precedentes, jurisprudência dominante, súmula, decisão judicial, tampouco, sobre as técnicas de superação e confronto dos precedentes, como overruling e distinguishing.

Vale ressaltar que as expressões "jurisprudência" e "precedente" são utilizadas de forma indistinta, como se fosse sinônimas. Todavia TARUFFO (2004, p. 03), destaca que existem entre elas uma nítida distinção, sobretudo de caráter quantitativo e qualitativo, pois quando se fala em precedente, geralmente se faz referência a uma única decisão sobre um caso particular, enquanto quando se fala em jurisprudência, faz-se referência a uma pluralidade de decisões relativas a vários e diversos casos concretos.

André Franco Montoro (2005, p. 410) define a jurisprudência como fonte do direito, e se apresenta como um conjunto uniforme e constante das decisões judiciais sobre casos semelhantes.

A jurisprudência é a reiterada aplicação de um precedente, podendo virar, inclusive, uma jurisprudência dominante que o próprio adjetivo já informa é a orientação que prevalece. Nos sistemas que se baseiam tradicionalmente e tipicamente no precedente, geralmente a decisão que assume caráter de precedente é um só, contudo, em sistemas como o nosso, faz-se referência a muitas decisões. (LOURENÇO, HAROLDO. Precedente Judicial como Fonte do Direito: algumas considerações sobre a ótica do novo CPC. Temas Atuais de Processo Civil. v.1; n.6; p. 09; 2011. Disponível em: <http://www.temasatuaisprocessocivil.com. br/ edicoes-anteriores/53-v1-n-6-dezembro-de-2011-/166-precedente-judicialcomo-fonte-do-direito-algumas-consideracoes-sob-a-otica-do-novo-cpc $>$. Acesso em: 12 de maio de 2016).

Constata-se que há um estímulo na publicação de enunciados sumulares, contudo não sequer investiga as circunstâncias dos casos que deram origem a sua edição, o que deveria ser imprescindível.

Infelizmente, pode-se verificar que o Novo Código de Processo Civil não desenvolveu o tema dos precedentes judiciais no Brasil como almejavam muitos juristas e operadores do Direito, ficando assim, a impressão de estar lendo o Código de Processo Civil de 1973, apenas reorganizado e repaginado, sem muitas mudanças significativas. 


\section{Considerações finais}

A aproximação entre os precedentes judiciais e o nosso sistema jurídico é um caminho sem volta, pois a favor ou contra, não se pode negar a teoria da força vinculante dos precedentes. Uma das grandes bandeiras do nosso sistema projetado é a ampliação dessa força vinculante, inclusive no tocante na fundamentação judicial, no qual o juiz terá que justificar fundamentadamente o porquê de não seguir o precedente, pois caso não haja fundamentação, a decisão é nula. A fundamentação é vinculada.

O processo de interpretação divergente é rechaçado pelo Novo Código de Processo Civil. A divergência interpretativa é um ponto negativo, sendo que alguns Tribunais brasileiros inclusive leva em conta o número de sentenças reformadas.

Acredita-se ser necessário enfrentar e trabalhar uma teoria do processo repetitivo onde o direito de ação e acesso à jurisdição, necessita ser repensado. O processo deve estar aberto ao diálogo, principalmente utilizando técnicas e experiências de outros sistemas, mas acima de tudo que seja adequado à nossa realidade brasileira, pois de nada adianta "copiar" um sistema que não tenha aplicabilidade ao direito brasileiro.

Não obstante todos os esforços empreendidos, percebe-se que a nossa jurisprudência ainda carece de uniformidade e estabilidade.

Além disso, observou-se que a resistência verificada no Brasil em implantar institutos que privilegiem a força normativa das decisões proferidas pelos órgãos judiciais, sobretudo às cortes superiores, deriva provavelmente do fato de estar enraizada em nossa tradição jurídica o ideal histórico da supremacia da lei sobre todas as outras fontes jurídicas, o que relegou a jurisprudência a um segundo plano e dificultou até hoje a formação de uma cultura sólida que atribua autoridade à jurisprudência.

Ademais ainda foram expostas e analisadas as principais razões para se conferir força obrigatória aos precedentes, bem como citado alguns argumentos contrários a obrigatoriedade de segui-los. Assim, também foi possível observar motivos favoráveis à sua observância, como forma de se alcançar a uniformidade e estabilidade da jurisprudência.

O presente trabalho visou contribuir com os debates acadêmicos, pois com a vigência e disposições sobre o tema elencados no Novo Código de Processo Civil, deverão ser colocadas em prática e garantida sua eficácia e aplicação no direito brasileiro. 


\section{Referências}

AGRA, Walber de Moura. Curso de direito constitucional. Rio de Janeiro: Forense, 2008.

BRASIL. Código de Processo Civil. Disponível em VADE MECUM. 8. ed. São Paulo: Saraiva, 2009.

Constituição da República Federativa do Brasil. Disponível em VADE MECUM. 8. ed. São Paulo: Saraiva, 2009.

CANOTILHO, José Joaquim Gomes. Direito constitucional e teoria da Constituição. 6. ed. Coimbra: Almedina,1993.

CUNHA, Leonardo Carneiro da. O processo civil no estado constitucional e os fundamentos do projeto do novo código de processo civil brasileiro. São Paulo, 2012. Disponível em http:/ / revistadostribunais.com.br/.Acesso em 22 de janeiro de 2016.

DIDIER JR, Fredie; OLIVEIRA, Rafael; BRAGA, Paula. Curso de Direito Processual Civil. Salvador: Juspodvm, 2013.

DIDIER JR, Fredie. Curso de Direito Processual Civil. v. II. 6. ed. Salvador: JusPodivum, 2011.

DONIZETTI, Elpídio. A força dos precedentes no novo código de processo civil. Salvador, 2015. Disponível em: http:/ / revistas.unifacs.br/index.php/redu/article/ view/3446/2472. Acesso em 20 de janeiro de 2016.

DONIZETTI, Elpídio. Expressa Constitucionalização do Direito Processual Civil (positivação do "totalitarismo constitucional"). Minas Gerais, 2012. Disponível em: <http://elpidiodonizetti.jusbrasil.com.br/artigos/121940194/expressa-constitucionalizacao-do-direito-processual-civil-positivacao-do-totalitarismo-constitucional>. Acesso em: 16 de maio de 2016.

DONIZETTI, Elpídio. A Força dos Precedentes no Novo Código de Processo Civil. Minas Gerais, 2012. Disponível em: <http://www.tjmg.jus.br/data/files/7B/96/ D0/66/2BCCB4109195A3B4E81808A8/A\%20forca\%20dos\%20precedentes\%20no\%20 novo $\% 20$ Codigo\%20de\%20Processo\%20Civil.pdf>. Acesso em 18 de março de 2016. 
LENZA, Pedro. Direito Constitucional Esquematizado. 16. ed. São Paulo: Editora Saraiva, 2012.

LIMA, Tiago Asfor Rocha. Precedentes Judiciais Civis no Brasil. São Paulo: Saraiva, 2013.

LOURENÇO, HAROLDO. Precedente Judicial como Fonte do Direito: algumas considerações sobre a ótica do novo CPC. Temas Atuais de Processo Civil. v. 1. n. 6. p. 09. Dezembro de 2011. Disponível em: <http://www.temasatuaisprocessocivil. com.br/edicoes-anteriores/53-v1-n-6-dezembro-de-2011-/166-precedente-judicialcomo-fonte-do-direito-algumas-consideracoes-sob-a-otica-do-novo-cpc>. Acesso em: 12 de maio de 2016.

MARINONI, Luiz Guilherme. Precedentes obrigatórios. São Paulo: Editora Revista dos Tribunais, 2010.

MONTORO, André Franco. Introdução à ciência do direito. 26. ed. São Paulo: Editora Revista dos Tribunais, 2005.

SILVA, Virgilio Afonso da. A Constitucionalização do Direito. São Paulo: Malheiros, 2008.

STRECK, Lenio Luiz; ABBOUD, Georges. O que é isto - o precedente judicial e as súmulas vinculantes? v. 3. Porto Alegre: Livraria do Advogado, 2013.

TUCCI, José Rogério Cruz e. Precedente Judicial como Fonte do Direito. São Paulo: Revista dos Tribunais, 2004.

WAMBIER, Teresa Arruda Alvim. Estabilidade e adaptabilidade como objetivos do direito: civil law e commow law. Revista de Processo. São Paulo, v. 172. jun 2009. 